Research Article

\title{
An Experimental Study of Seepage Properties in Crushed Sandstone and Mudstone
}

\author{
Qi-Le Ding $\mathbb{D D}^{1}$ and Shuai-Bing Song $\mathbb{D}^{2}$ \\ ${ }^{1}$ School of Environment and Civil Engineering, Dongguan University of Technology, 523080 Dongguan, China \\ ${ }^{2}$ State Key Laboratory for Geomechanics and Deep Underground Engineering, China University of Mining and Technology, \\ 221116 Xuzhou, China \\ Correspondence should be addressed to Qi-Le Ding; leqiding@hotmail.com
}

Received 14 March 2019; Accepted 28 May 2019; Published 18 June 2019

Academic Editor: Damien Rangeard

Copyright (c) 2019 Qi-Le Ding and Shuai-Bing Song. This is an open access article distributed under the Creative Commons Attribution License, which permits unrestricted use, distribution, and reproduction in any medium, provided the original work is properly cited.

\begin{abstract}
To study the effects of compression rate and weight ratio of sandstone to mudstone on permeability, water flow tests were performed on crushed rocks using an in-house designed and built water flow apparatus. Seepage properties of sandstone and mudstone were tested on specimens under six axial displacement levels. The weight ratios of the six specimens of sandstone to mudstone were set to $1: 0,4: 1,3: 2,2: 3,1: 4$, and $0: 1$. A non-Darcy law was adopted to calculate the permeability in the experiments based on verification of the Reynolds number. Non-Darcy flow is found to be most significant when the axial displacement or mudstone content increases. The permeability in the experiments is found to be in the range of $9.1 \times 10^{-15}-9.492 \times 10^{-13} \mathrm{~m}^{2}$, which is calculated from a quadratic polynomial fit between the flow velocity and pressure gradient. A compression rate of $28.6 \%$ and weight ratio of sandstone to mudstone of $60 \%$ are found to be key values affecting permeability. When the axial displacement of specimen A (1:0) increases from $10 \mathrm{~mm}$ to $30 \mathrm{~mm}$, the compression rate (ratio of axial displacement to original specimen height) increases from $9.5 \%$ to $28.6 \%$, and the permeability decreases by $83.8 \%$ to $1.534 \times 10^{-13} \mathrm{~m}^{2}$. When the axial displacement is $10 \mathrm{~mm}$ and the content of mudstone is increased from $0 \%$ to $60 \%$, the permeability decreases by $77.1 \%$ to $2.172 \times 10^{-13} \mathrm{~m}^{2}$.
\end{abstract}

\section{Introduction}

Underground mining can lead to strata movement and loss of equilibrium of the stress state, causing deterioration in the mechanical behavior of surrounding rocks [1-3]. Schatzel et al. [4] tested water flow properties of overburden strata at a mine site and demonstrated that the permeability increased by two to three orders of magnitude as a result of mining disturbance. Advancement of the working face may result in a series of hazards, such as groundwater inrush into a coal mine from an aquifer, which is one of the most frequent forms of mining accidents [5-7]. This type of accident seriously threatens safe production of the mine, and mine workers themselves $[8,9]$. Since 2000, about 500 events of mine water inrush have occurred in China and more than 3000 people have lost their lives. For example, 36 people died in a groundwater inrush accident at the Wangjialing Coal
Mine in Shanxi Province, China, on 28 March 2010 [8]. In recent years, and with continuing extension to more complex coal seams containing faults, karst collapse pillars and other weak tectonic structures, the hydrogeological conditions in such mines are deteriorating $[10,11]$.

Many scholars have studied the mechanics and the prediction and the control measures of water inrush [12-15]. Bukowski [16] proposed a risk assessment method to classify mine shafts according to the risk of water inrush. The method considers factors such as flow intensity, condition of waterbearing formations, suspended materials contained in the water, and protective coal pillars. Wu et al. [11] adopted the "three maps-two predictions" method to construct an index model of water abundance in overlying aquifers, with results shown on a map indicating potential water flow channels to aquifers.

A more accurate and in-depth understanding of seepage properties is important for prediction and control 
of mine water inrush accidents [17], and the study of permeability of rocks is the foundation of such. Tanikawa and Shimamoto [18] carried out water permeability tests on sedimentary rocks from the western foothills of Taiwan and found that the permeability increased slightly when the pressure gradient increased. Benavente et al. [19] studied the water permeability of 15 sedimentary rock types and proposed a model for calculating permeability that considers factors such as flow velocity, water properties (density and viscosity), porosity, interfacial tension, and contact angle.

Research into the permeability of rocks mainly focuses on intact rocks that have not been broken or damaged, while crushed rocks are widely distributed in fault zones, karst collapse pillars, and caved zones. These crushed rocks, of which the permeability is much higher than intact rock [20-25], may act as preferential migration pathways for groundwater into a mine [26].

In this paper, the effects of compression rate and weight ratio of sandstone to mudstone on permeability are investigated using an in-house designed and built water flow apparatus. Water flow tests were performed on crushed rocks containing sandstone and mudstone. The experimental results provide an improved understanding of the mechanism of water inrush through such preferential pathway materials and serve as a reference for prediction and control of water inrush accidents.

\section{Experimental Materials and Testing Procedures}

2.1. Experimental Materials. The sandstone and mudstone used in the experiments were collected from the 21105 working face of the Pingshuo Coal Mine in Shanxi Province, China. The mineral composition of the tested sandstone and mudstone was composed of feldspar, quartz, kaolinite, chlorite, siderite, and small amounts of other minerals. The sandstone and mudstone blocks were crushed using a hammer, piercer, and rock crusher in the laboratory. A sieve was used to separate the particles in the $10-15 \mathrm{~mm}$ size range, as shown in Figure 1. This size range closely correlates with site conditions, as $10-15 \mathrm{~mm}$ size sandstone and mudstone grains are typically widely distributed in fault zones, collapse pillars, and caved zones. Six specimens were made, each with a different weight ratio of sandstone to mudstone. These specimen were A $(1: 0), \mathrm{B}(4: 1), \mathrm{C}(3: 2)$, $\mathrm{D}(2: 3), \mathrm{E}(1: 4)$, and $\mathrm{F}(0: 1)$, the ratios of sandstone to mudstone shown in parentheses.

2.2. Experimental Equipment and Testing Procedures. The experimental apparatus is illustrated in Figure 2. The details of the apparatus setup are provided in the figure caption.

The testing procedures are conducted in two main steps, as described in detail as follows.

(1) The axial displacement $(S)$ is applied. Six axial displacement levels were set: $10 \mathrm{~mm}, 15 \mathrm{~mm}, 20 \mathrm{~mm}$, $25 \mathrm{~mm}, 30 \mathrm{~mm}$, and $35 \mathrm{~mm}$. The target value was applied to the specimen and maintained until step
(2) was completed, as shown in Figure 3. The porosity $(\varphi)$ of the crushed rocks was calculated as follows:

$$
\varphi=\frac{A H_{n}-(m / \rho)}{A H_{n}},
$$

where $A$ is the cross sectional area of the inner wall of the cylindrical barrel $\left(1.27 \times 10^{-2} \mathrm{~m}^{2}\right), m$ is the mass (1.7 kg), $\rho$ is the density, and $H_{n}$ is the height of specimen at a given axial displacement and is calculated as follows:

$$
H_{n}=H-\left(110-h_{n}\right)-\left(h_{2}+h_{3}\right),
$$

where $H$ is the height of the cylindrical barrel $(180 \mathrm{~mm}), h_{n}$ is the length of part of piston that is outside of the cylindrical barrel (variable according to the six different axial displacement levels), $h_{2}$ is the thickness of the perforated plate $(9 \mathrm{~mm})$, and $h_{3}$ is the thickness of the felt pad $(3 \mathrm{~mm})$.

(2) Water flow testing is undertaken. When the axial displacement becomes stable, a pore pressure control system is used to produce four different piston velocities: 10, 20, 30, and $35 \mathrm{~mm} / \mathrm{min}$. The relation between water flow velocity $\left(V_{\mathrm{s}}\right)$ and piston velocity $\left(V_{\mathrm{p}}\right)$ is written as follows:

$$
V_{\mathrm{s}}=\left(\frac{d_{\mathrm{p}}}{d_{\mathrm{s}}}\right)^{2} V_{\mathrm{p}}
$$

where $d_{\mathrm{s}}$ and $d_{\mathrm{p}}$ are the respective diameters of the specimen and the piston $(12.7 \mathrm{~cm}$ and $5.5 \mathrm{~cm}$, respectively). Thus, it is possible to obtain the pressure gradient and corresponding water flow velocities.

\section{Permeability Calculation Based on a Non-Darcy Flow}

The Forchheimer equation has been proven to accurately quantify water flow in crushed rock when water flow is stable $[27,28]$. The value of the pressure gradient relative to flow velocity can be expressed as follows:

$$
\frac{\partial p}{\partial x}=-\frac{\mu}{k} V_{\mathrm{s}}+\beta \rho_{\mathrm{w}} V_{\mathrm{s}}^{2}
$$

where $\mu$ is the dynamic viscosity (tap water was used in the experiment: $\left.\mu=1.01 \times 10^{-9} \mathrm{MPa} \cdot \mathrm{s}\right), k$ is the permeability, $\rho_{\mathrm{w}}$ is the mass density of the fluid medium $\left(1.0 \times 10^{-6} \mathrm{~kg} / \mathrm{mm}^{3}\right)$, and $\beta$ is a factor of non-Darcy seepage.

The non-Darcy equation (4) adopted in the experiments is verified by the Reynolds number Re, which is calculated as follows:

$$
\operatorname{Re}=\frac{\rho_{\mathrm{w}} d V_{\mathrm{s}}}{\varphi \mu},
$$

where $d$ is the average grain size of the crushed rocks $(10-15 \mathrm{~mm})$. Earlier studies have shown that the upper limit of Re is 5 when using Darcy law, and non-Darcy flow can be adopted when $\mathrm{Re}>5$. In our experiments, the minimum and 


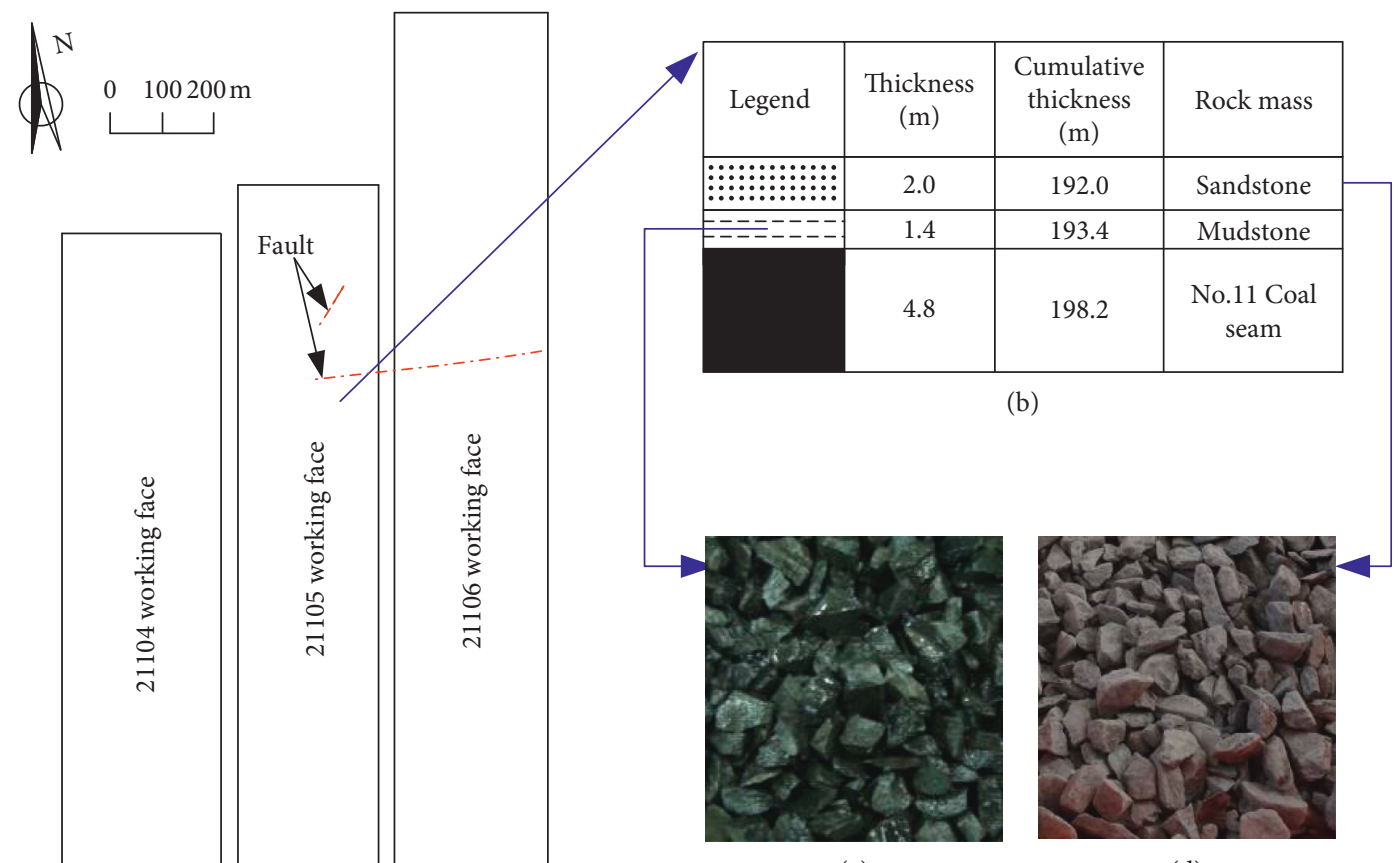

(c)

(d)

(a)

FIgURe 1: Illustration of the geological conditions and sample material showing (a) working faces of the Pingshuo coal mine, (b) borehole log showing the lithologies, (c) crushed mudstone, and (d) crushed sandstone.

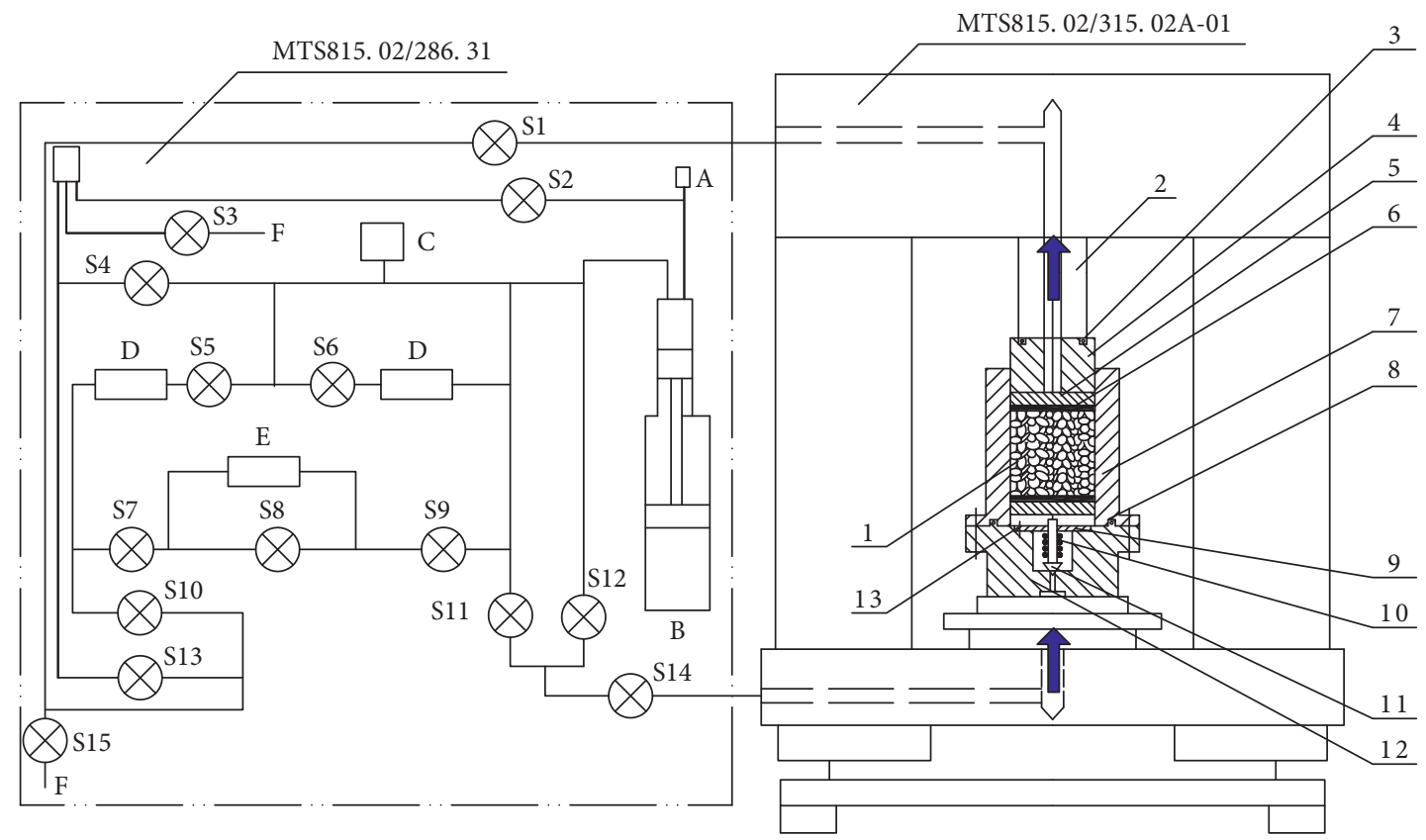

Figure 2: Water flow testing system. A, pressure transducer; B, supercharger; C, relief valve; D, voltage stabilizer; E, differential pressure transducer; F, drainage; S1-S15, switches; 1, crushed rocks; 2, platen; 3 and 8, rubber seal rings; 4, piston; 5, perforated plate; 6, felt pad; 7, cylindrical barrel; 9, plate; 10, spring; 11, valve core; 12, valve chest; and 13, screw.

maximum values of Re were 0.72 and 10.09 , respectively. Thus, non-Darcy flow is more applicable.

There is a difference between the base pressure $P_{\mathrm{b}}$ and top pressure $P_{\mathrm{t}}$ of the specimen, and the pressure gradient, shown in (6), is approximately equal to the ratio of pressure difference to specimen height $h$. The downstream end is open to the atmosphere in the testing system, thus $P_{\mathrm{t}}=0$ : 


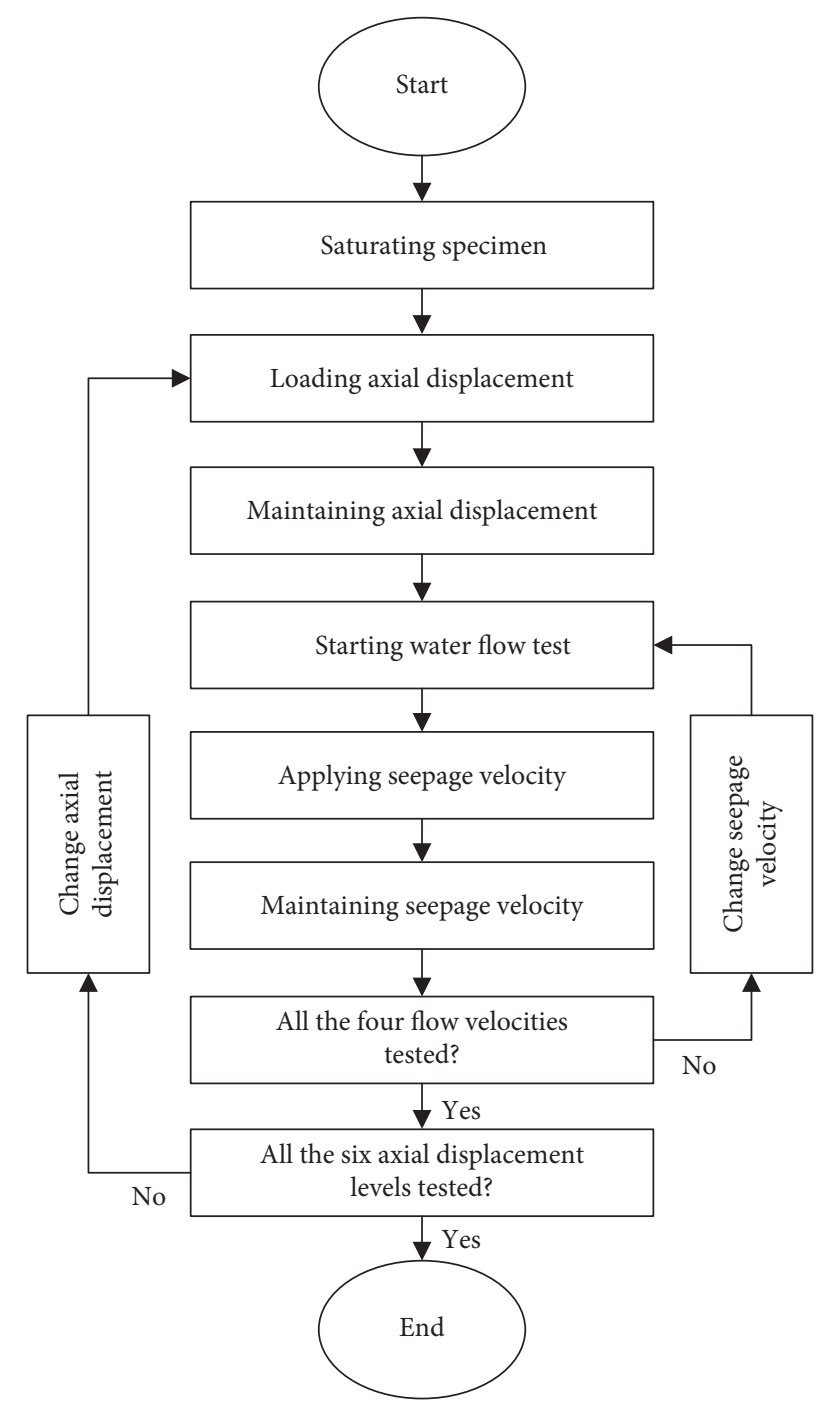

FIGURE 3: Water flow testing procedure of the crushed sandstone and mudstone samples.

$$
\frac{\partial p}{\partial x}=-\frac{p_{\mathrm{b}}-p_{\mathrm{t}}}{h}=-\frac{p_{\mathrm{b}}}{h}
$$

The permeability $k$ is calculated from the quadratic polynomial fit between the flow velocity and the corresponding pressure gradient as follows:

$$
\frac{\mu}{k}=\frac{\left.\sum_{i=1}^{n}(\partial p / \partial x)\right|_{i} V_{i}(i) \sum_{k=1}^{n} V_{k}^{4}(k)-\left.\sum_{i=1}^{n}(\partial p / \partial x)\right|_{i} V_{i}^{2}(i) \sum_{k=1}^{n} V_{k}^{3}(k)}{\sum_{i=1}^{n} V_{i}^{2}(i) \sum_{k=1}^{n} V_{k}^{4}(k) \sum_{i=1}^{n} V_{i}^{3}(i) \sum_{k=1}^{n} V_{k}^{3}(k)} .
$$

\section{Test Results and Discussion}

As the water flow tests began, the pore pressure gradually increased, reaching a stable state after about 20 seconds (Figure 4). It was found that a piston velocity of $10 \mathrm{~mm} /$ min corresponds to the first axial displacement level in the water flow test, and the $10 \mathrm{~mm} / \mathrm{min}$ curves show more significant changes than other curves as time increases.

The positions and distributions of the constituent grains changed as the tests continued, leading to the unstable state of the curves. The $10 \mathrm{~mm} / \mathrm{min}$ curve in Figure 4(a) and the $20 \mathrm{~mm} / \mathrm{min}$ curve in Figure 4(c) both show a significant decrease before the water flow stabilized. This resulted from the evolution of water flow channels. When the water flow tests were started, the channels through which water flows had not formed completely, and pore pressure was increasing sharply. As water flow continued, the channels became smoother, leading to a decrease in pore water pressure.

Values of water flow velocity $\left(V_{s}\right)$, the corresponding pressure gradient, and the calculated permeability $k$ are provided in Table 1 , and the relationship between the pressure gradient and the flow velocity is shown in Figures 5 and 6 . As the axial displacement and the content of mudstone increase, the curves of pressure gradient vs. flow velocity change from straight lines to curves. That is, the phenomenon of non-Darcy flow is most significant when the porosity decreases. The relationship between the pressure gradient and the axial displacement is shown in Figure 7 . The permeability $k$ was calculated from the quadratic polynomial fitting between the pressure gradient and flow velocity $\left(V_{\mathrm{s}}\right)$.

Table 2 shows that the permeability of crushed rocks in the tests was in the range of $9.1 \times 10^{-15}-9.492 \times 10^{-13} \mathrm{~m}^{2}$, which is an approximate two orders of magnitude increase compared to fractured sandstone [29].

Figure 8 demonstrates that the permeability is closely correlated with the compression state and, when the axial displacement increases, the porosity decreases, resulting in a decrease in permeability. The decreasing rate is most significant when the axial displacement increased from $10 \mathrm{~mm}$ to $30 \mathrm{~mm}$. As the axial displacement of specimen A $(1: 0)$ increased from $10 \mathrm{~mm}$ to $30 \mathrm{~mm}$, the compression rate (ratio of axial displacement to original specimen height) increased from $9.5 \%$ to $28.6 \%$, the porosity decreased from 0.427 to 0.275 , and the permeability decreased by $83.8 \%$ from $9.492 \times 10^{-13}$ to $1.534 \times 10^{-13} \mathrm{~m}^{2}$. When the axial displacement increased to $35 \mathrm{~mm}$, the permeability decreased slightly and the difference in permeability among different specimens decreased when the axial displacement increased.

For specimens with the same axial displacement, a higher content of mudstone led to a decrease in porosity and thus a decrease in permeability (Figure 9). When the content of mudstone increased from $0 \%$ to $60 \%$, the changing rate of permeability was most significant. When the axial displacement was $10 \mathrm{~mm}$ and the content of mudstone increased from $0 \%$ to $60 \%$, the porosity decreased from 0.427 to 0.400 and the permeability decreased by $77.1 \%$ from $9.492 \times 10^{-13}$ to $2.172 \times 10^{-13} \mathrm{~m}^{2}$. The decreasing rate of permeability declined when the content of mudstone was $>60 \%$. As the mudstone content increased, the difference in permeability among different axial displacement levels decreased. 


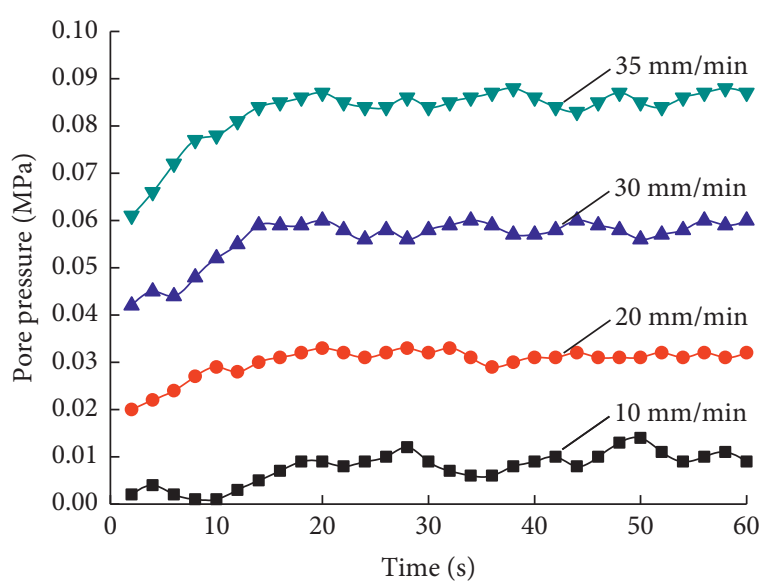

(a)

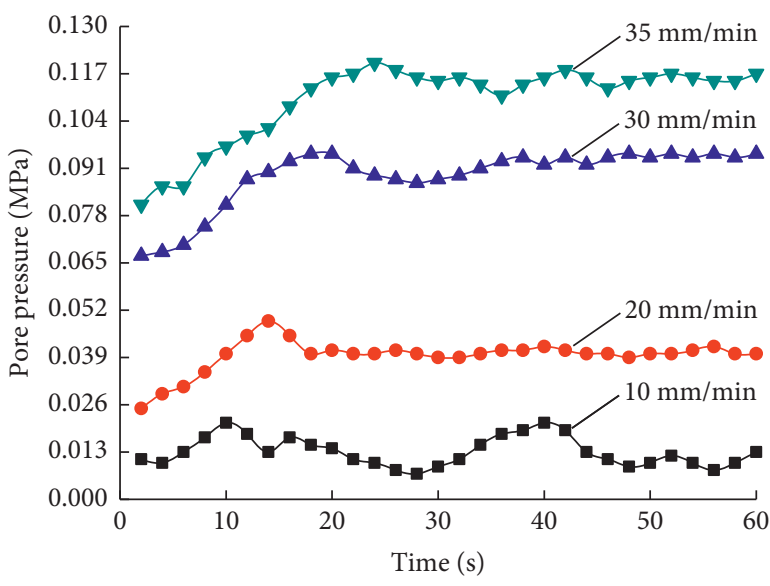

(c)

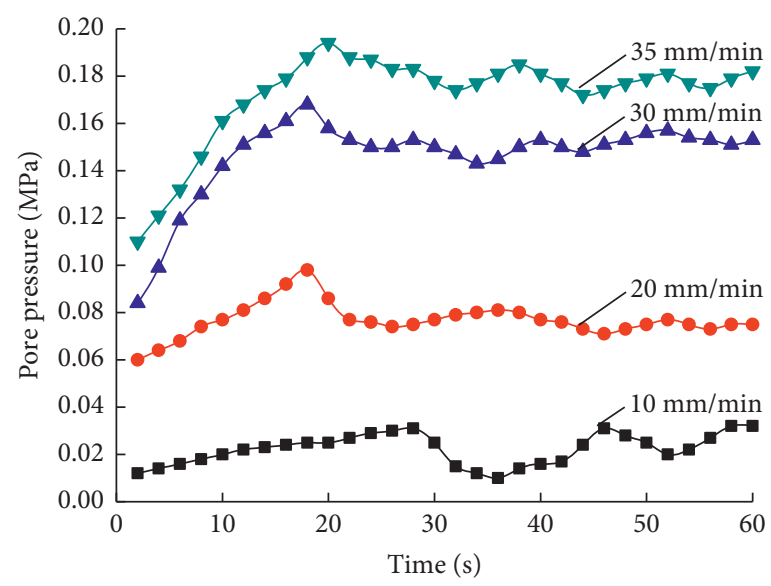

(e)

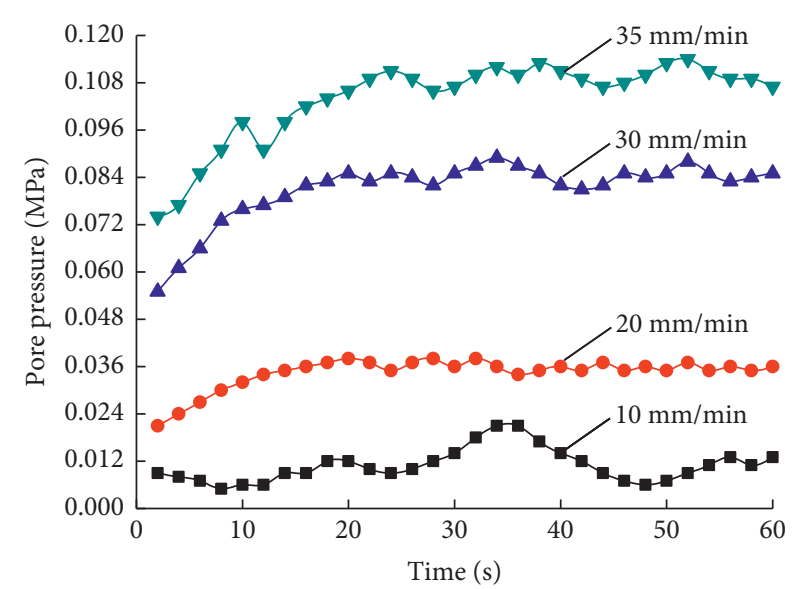

(b)

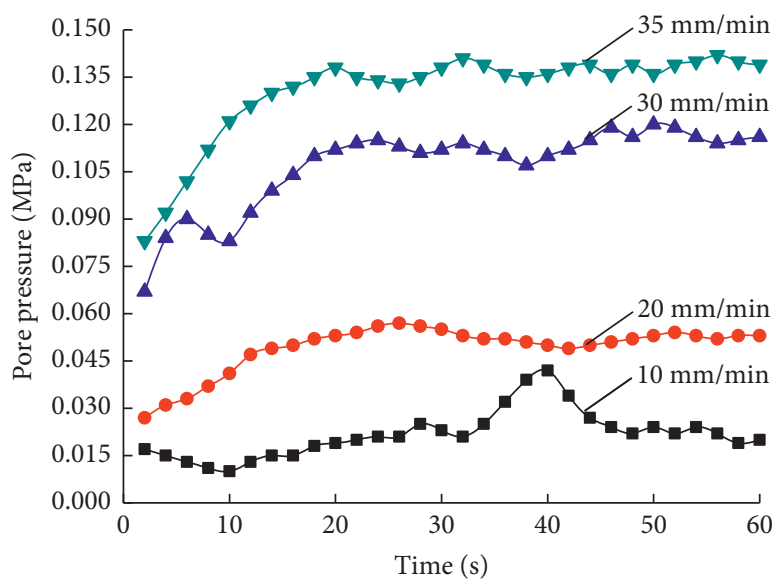

(d)

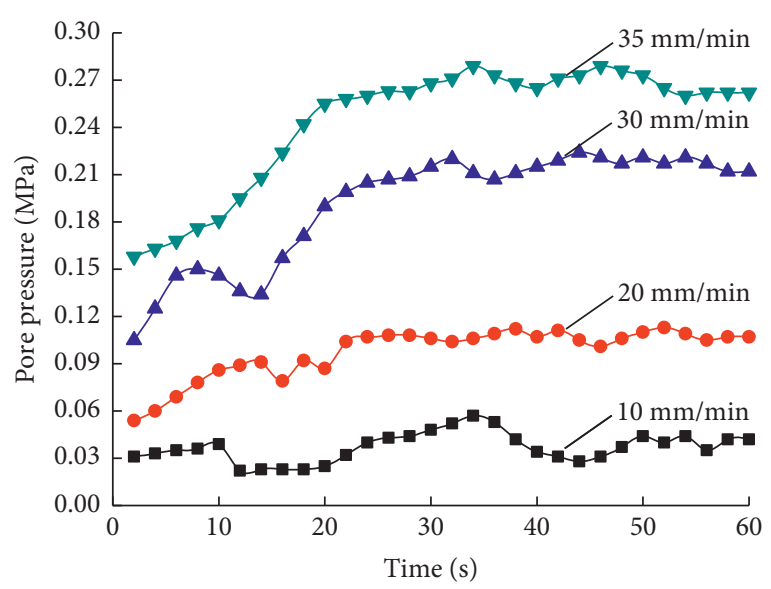

(f)

FIGURE 4: Graphs of pore water pressure vs. time at various axial displacement levels of specimen A (1:0): (a) axial displacement 10 mm (compression rate 9.5\%); (b) axial displacement $15 \mathrm{~mm}$ (compression rate 14.3\%); (c) axial displacement $20 \mathrm{~mm}$ (compression rate 19.0\%); (d) axial displacement $25 \mathrm{~mm}$ (compression rate 23.8\%); (e) axial displacement $30 \mathrm{~mm}$ (compression rate 28.6\%); (f) axial displacement $35 \mathrm{~mm}$ (compression rate $33.3 \%$ ).

\section{Conclusions}

Based on the work presented, the following conclusions can be drawn regarding the experiment and the results thereof:
(1) Stable water flow in the flow tests is achieved after about 20 seconds, and the pore water pressure showed most significant changes at the first velocity levels for each axial displacement. 
TABLE 1: Pressure gradient and flow velocity parameters of specimen A $(1: 0)$.

\begin{tabular}{|c|c|c|c|c|}
\hline $\begin{array}{l}\text { Axial displacement } \\
S(\mathrm{~mm})\end{array}$ & $\begin{array}{l}\text { Piston velocity } \\
V_{\mathrm{p}}(\mathrm{mm} / \mathrm{min})\end{array}$ & Flow velocity $V_{\mathrm{s}}(\mathrm{m} / \mathrm{s})$ & $\begin{array}{l}\text { Pressure gradient } \partial p / \partial x \\
\qquad(\mathrm{MPa} / \mathrm{m})\end{array}$ & $\begin{array}{c}\text { Permeability } \\
k\left(\mathrm{~m}^{2}\right)\end{array}$ \\
\hline \multirow{4}{*}{10} & 10 & $3.13 \times 10^{-5}$ & -0.09 & \multirow{4}{*}{$9.49 \times 10^{-13}$} \\
\hline & 20 & $6.25 \times 10^{-5}$ & -0.33 & \\
\hline & 30 & $9.38 \times 10^{-5}$ & -0.60 & \\
\hline & 35 & $1.09 \times 10^{-4}$ & -0.87 & \\
\hline \multirow{4}{*}{15} & 10 & $3.13 \times 10^{-5}$ & -0.12 & \multirow{4}{*}{$6.84 \times 10^{-13}$} \\
\hline & 20 & $6.25 \times 10^{-5}$ & -0.38 & \\
\hline & 30 & $9.38 \times 10^{-5}$ & -0.85 & \\
\hline & 35 & $1.09 \times 10^{-4}$ & -1.06 & \\
\hline \multirow{4}{*}{20} & 10 & $3.13 \times 10^{-5}$ & -0.14 & \multirow{4}{*}{$5.83 \times 10^{-13}$} \\
\hline & 20 & $6.25 \times 10^{-5}$ & -0.41 & \\
\hline & 30 & $9.38 \times 10^{-5}$ & -0.95 & \\
\hline & 35 & $1.09 \times 10^{-4}$ & -1.16 & \\
\hline \multirow{4}{*}{25} & 10 & $3.13 \times 10^{-5}$ & -0.19 & \multirow{4}{*}{$3.05 \times 10^{-13}$} \\
\hline & 20 & $6.25 \times 10^{-5}$ & -0.53 & \\
\hline & 30 & $9.38 \times 10^{-5}$ & -1.12 & \\
\hline & 35 & $1.09 \times 10^{-4}$ & -1.38 & \\
\hline \multirow{4}{*}{30} & 10 & $3.13 \times 10^{-5}$ & -0.31 & \multirow{4}{*}{$1.53 \times 10^{-13}$} \\
\hline & 20 & $6.25 \times 10^{-5}$ & -0.75 & \\
\hline & 30 & $9.38 \times 10^{-5}$ & -1.53 & \\
\hline & 35 & $1.09 \times 10^{-4}$ & -1.83 & \\
\hline \multirow{4}{*}{35} & 10 & $3.13 \times 10^{-5}$ & -0.44 & \multirow{4}{*}{$1.12 \times 10^{-13}$} \\
\hline & 20 & $6.25 \times 10^{-5}$ & -1.08 & \\
\hline & 30 & $9.38 \times 10^{-5}$ & -2.09 & \\
\hline & 35 & $1.09 \times 10^{-4}$ & -2.63 & \\
\hline
\end{tabular}

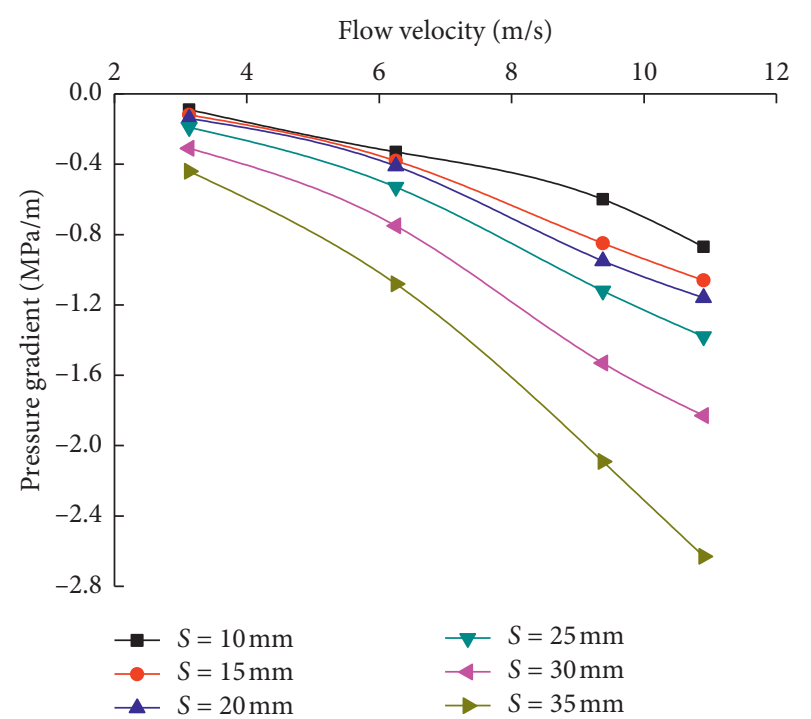

FIGURE 5: Flow velocity and corresponding pressure gradient of specimen A (1:0) under different axial displacements $(S)$.

(2) Non-Darcy flow was adopted for calculations of the permeability, based on the verification of the Reynolds number. Non-Darcy flow was most significant when the axial displacement or the mudstone content increased.

(3) Permeability of the crushed rock samples was in the $9.1 \times 10^{-15}-9.492 \times 10^{-13} \mathrm{~m}^{2}$ range, which correlates



FIGURE 6: Flow velocity and corresponding pressure gradient of all the specimens when the axial displacement is $10 \mathrm{~mm}$.

closely with the level of axial displacement and mudstone content.

(4) The permeability decreases most significantly when the axial displacement increased from $10 \mathrm{~mm}$ to $30 \mathrm{~mm}$. When the axial displacement of specimen A (1:0) increased from $10 \mathrm{~mm}$ to $30 \mathrm{~mm}$, the compression rate increased from $9.5 \%$ 




FIGURE 7: Axial displacement and corresponding pressure gradient of specimen A (1:0) under different piston velocities.

TABle 2: Porosity $(\varphi)$ and permeability $(k)$ at various axial displacements for all the specimens.

\begin{tabular}{|c|c|c|c|c|c|c|c|}
\hline \multirow{2}{*}{ Specimen number } & \multirow{2}{*}{ Properties } & \multicolumn{6}{|c|}{ Axial displacement $(\mathrm{mm})$} \\
\hline & & 10 & 15 & 20 & 25 & 30 & 35 \\
\hline \multirow{2}{*}{$\mathrm{A}(1: 0)$} & \multirow{2}{*}{$\begin{array}{c}\varphi \\
k\left(\times 10^{-14}\right) \\
\end{array}$} & 0.427 & 0.396 & 0.360 & 0.320 & 0.275 & 0.223 \\
\hline & & 94.92 & 68.43 & 58.31 & 30.51 & 15.34 & 11.20 \\
\hline \multirow{2}{*}{$\mathrm{B}(4: 1)$} & \multirow{2}{*}{$\begin{array}{c}\varphi \\
k\left(\times 10^{-14}\right)\end{array}$} & 0.420 & 0.387 & 0.352 & 0.311 & 0.266 & 0.214 \\
\hline & & 47.80 & 38.40 & 39.72 & 18.85 & 11.81 & 8.23 \\
\hline \multirow{2}{*}{$\mathrm{C}(3: 2)$} & \multirow{2}{*}{$\begin{array}{c}\varphi \\
k\left(\times 10^{-14}\right)\end{array}$} & 0.409 & 0.377 & 0.341 & 0.300 & 0.254 & 0.201 \\
\hline & & 45.99 & 33.81 & 27.97 & 16.32 & 6.31 & 5.11 \\
\hline \multirow{2}{*}{$\mathrm{D}(2: 3)$} & \multirow{2}{*}{$\begin{array}{c}\varphi \\
k\left(\times 10^{-14}\right)\end{array}$} & 0.400 & 0.368 & 0.331 & 0.290 & 0.244 & 0.191 \\
\hline & & 21.72 & 20.35 & 12.46 & 9.30 & 3.94 & 2.98 \\
\hline \multirow{2}{*}{$\mathrm{E}(1: 4)$} & \multirow{2}{*}{$\begin{array}{c}\varphi \\
k\left(\times 10^{-14}\right)\end{array}$} & 0.389 & 0.356 & 0.319 & 0.277 & 0.231 & 0.177 \\
\hline & & 12.79 & 8.94 & 7.32 & 4.60 & 3.34 & 1.20 \\
\hline \multirow{2}{*}{$\mathrm{F}(0: 1)$} & \multirow{2}{*}{$\begin{array}{c}\varphi \\
k\left(\times 10^{-14}\right)\end{array}$} & 0.376 & 0.343 & 0.305 & 0.263 & 0.216 & 0.161 \\
\hline & & 6.16 & 4.71 & 3.38 & 2.62 & 1.06 & 0.91 \\
\hline
\end{tabular}

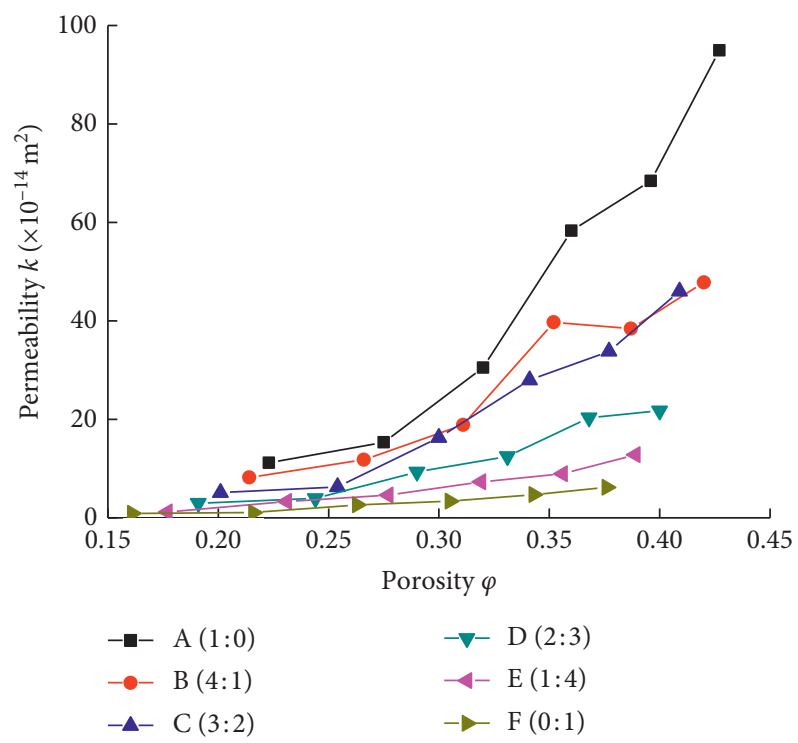

FIGURE 8: Permeability as a function of porosity of all the specimens (A-F). 


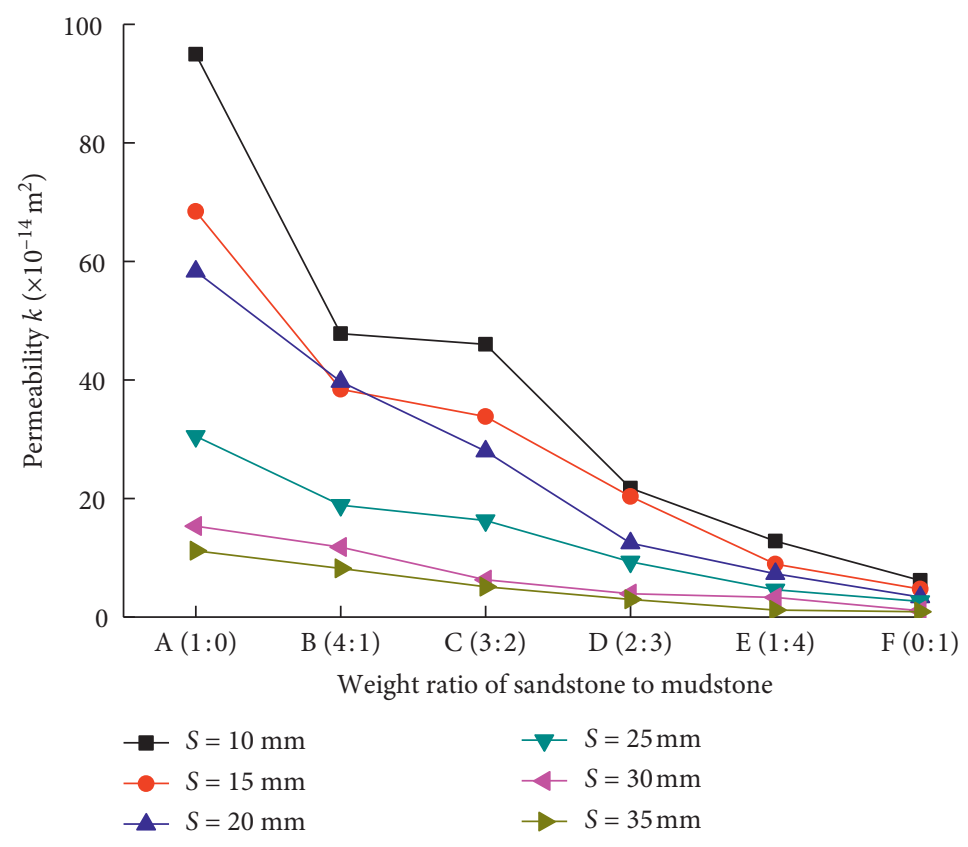

FIgURe 9: Permeability as a function of increasing mudstone content in samples subjected to different axial displacements $(S)$.

to $28.6 \%$, the porosity decreased from 0.427 to 0.275 , and the permeability decreased by $83.8 \%$ from $9.492 \times 10^{-13}$ to $1.534 \times 10^{-13} \mathrm{~m}^{2}$. When the mudstone content was increased from $0 \%$ to $60 \%$, the changing rate of permeability was most significant. When the axial displacement was $10 \mathrm{~mm}$ and the mudstone content increased from $0 \%$ to $60 \%$, the porosity decreased from 0.427 to 0.400 , and the permeability decreased by $77.1 \%$ from $9.492 \times 10^{-13}$ to $2.172 \times 10^{-13} \mathrm{~m}^{2}$.

\section{Data Availability}

The data used to support the findings of this study are available from the corresponding author upon request.

\section{Conflicts of Interest}

The authors declare that they have no conflicts of interest.

\section{Acknowledgments}

This work was supported by the Initial Scientific Research Fund of Young Teachers in Dongguan University of Technology (grant no. GC300501-069), the Social Science and Technology Development Program of Dongguan (major, grant nos. 2017507140429 and 20185071401603 ), the Guangdong Natural Science Foundation (grant no. 2018A030313864), the Research on Key Problems of Rail Flaw Detection Based on Ultrasound Guided Waves (grant no. 2016KZDXM053), and the Undergraduate Training Program for Innovation and Entrepreneurship (grant nos. 201811819109, 201811819382, and 201911819028).

\section{References}

[1] Z. Chai, J. Bai, H. Zhang, and P. Yang, "Evolution rules of fractures for mudstone under compression shear load and the fractal characteristics of broken blocks," Advances in Civil Engineering, vol. 2019, Article ID 2489218, 7 pages, 2019.

[2] Q.-L. Ding, F. Ju, X.-B. Mao, D. Ma, B.-Y. Yu, and S.-B. Song, "Experimental investigation of the mechanical behavior in unloading conditions of sandstone after high-temperature treatment," Rock Mechanics and Rock Engineering, vol. 49, no. 7, pp. 2641-2653, 2016.

[3] Q.-L. Ding and S.-B. Song, "Experimental investigation of the relationship between the P-wave velocity and the mechanical properties of damaged sandstone," Advances in Materials Science and Engineering, vol. 2016, Article ID 7654234, 10 pages, 2016

[4] S. J. Schatzel, C. Ö. Karacan, H. Dougherty, and G. V. R. Goodman, "An analysis of reservoir conditions and responses in longwall panel overburden during mining and its effect on gob gas well performance," Engineering Geology, vol. 127, no. 24, pp. 65-74, 2012.

[5] H. Chen, H. Qi, R. Long, and M. Zhang, "Research on 10-year tendency of China coal mine accidents and the characteristics of human factors," Safety Science, vol. 50, no. 4, pp. 745-750, 2012.

[6] X. He and L. Song, "Status and future tasks of coal mining safety in China," Safety Science, vol. 50, no. 4, pp. 894-898, 2012.

[7] D. Ma and H. Bai, "Groundwater inflow prediction model of karst collapse pillar: a case study for mining-induced groundwater inrush risk," Natural Hazards, vol. 76, no. 2, pp. 1319-1334, 2015.

[8] C. Li, J. Li, Z. Li, and D. Hou, "Establishment of spatiotemporal dynamic model for water inrush spreading processes in underground mining operations," Safety Science, vol. 55, pp. 45-52, 2013. 
[9] H. Q. Zhang, Y. N. He, C. A. Tang, B. Ahmad, and L. J. Han, "Application of an improved flow-stress-damage model to the criticality assessment of water inrush in a mine: a case study," Rock Mechanics and Rock Engineering, vol. 42, no. 6, pp. 911-930, 2009.

[10] Q. Wu, Y. Liu, L. Luo, S. Liu, W. Sun, and Y. Zeng, "Quantitative evaluation and prediction of water inrush vulnerability from aquifers overlying coal seams in Donghuantuo coal mine, China," Environmental Earth Sciences, vol. 74, no. 2, pp. 1429-1437, 2015.

[11] Q. Wu, Y. Liu, W. Zhou et al., "Evaluation of water inrush vulnerability from aquifers overlying coal seams in the Menkeqing coal mine, China," Mine Water and the Environment, vol. 34, no. 3, pp. 258-269, 2015.

[12] S. H. Chen, L. L. Xue, G. S. Xu, and I. Shahrour, "Composite element method for the seepage analysis of rock masses containing fractures and drainage holes," International Journal of Rock Mechanics and Mining Sciences, vol. 47, no. 5, pp. 762-770, 2010.

[13] N. Coli, G. Pranzini, A. Alfi, and V. Boerio, "Evaluation of rock-mass permeability tensor and prediction of tunnel inflows by means of geostructural surveys and finite element seepage analysis," Engineering Geology, vol. 101, no. 3-4, pp. 174-184, 2008.

[14] P. Li, W. Lu, Y. Long, Z. Yang, and J. Li, "Seepage analysis in a fractured rock mass: the upper reservoir of Pushihe pumpedstorage power station in China," Engineering Geology, vol. 97, no. 1-2, pp. 53-62, 2008.

[15] Y. N. Gao, F. Gao, Z. K. Wang, and P. Hou, "A comparative study on fracture characteristics of the red sandstone under water and nitrogen gas fracturing," Advances in Civil Engineering, vol. 2018, Article ID 1832431, 15 pages, 2018.

[16] P. Bukowski, "Water hazard assessment in active shafts in upper silesian coal basin mines," Mine Water and the Environment, vol. 30, no. 4, pp. 302-311, 2011.

[17] N. Nishiyama and T. Yokoyama, "Estimation of permeability of sedimentary rocks by applying water-expulsion porosimetry to Katz and Thompson model," Engineering Geology, vol. 177, pp. 75-82, 2014.

[18] W. Tanikawa and T. Shimamoto, "Comparison of Klinkenbergcorrected gas permeability and water permeability in sedimentary rocks," International Journal of Rock Mechanics and Mining Sciences, vol. 46, no. 2, pp. 229-238, 2009.

[19] D. Benavente, C. Pla, N. Cueto et al., "Predicting water permeability in sedimentary rocks from capillary imbibition and pore structure," Engineering Geology, vol. 195, pp. 301311, 2015.

[20] D. P. Adhikary and H. Guo, "Modelling of longwall mininginduced strata permeability change," Rock Mechanics and Rock Engineering, vol. 48, no. 1, pp. 345-359, 2015.

[21] C. Ö. Karacan, "Reconciling longwall gob gas reservoirs and venthole production performances using multiple rate drawdown well test analysis," International Journal of Coal Geology, vol. 80, no. 3-4, pp. 181-195, 2009.

[22] C. Ö. Karacan and G. Goodman, "Hydraulic conductivity changes and influencing factors in longwall overburden determined by slug tests in gob gas ventholes," International Journal of Rock Mechanics and Mining Sciences, vol. 46, no. 7, pp. 1162-1174, 2009.

[23] C. O. Karacan and G. V. R. Goodman, "Monte Carlo simulation and well testing applied in evaluating reservoir properties in a deforming longwall overburden," Transport in Porous Media, vol. 86, no. 2, pp. 445-464, 2011.
[24] M. R. M. Brown and M. Liu, "Injection-induced seismicity in carbon and emery counties, central Utah," Geofluids, vol. 16, no. 5, pp. 801-812, 2016.

[25] Q. Lin, P. Cao, H. Wang, and R. Cao, "An experimental study on cracking behavior of precracked sandstone specimens under seepage pressure," Advances in Civil Engineering, vol. 2018, Article ID 4068918, 10 pages, 2018.

[26] B. Zhu, Q. Wu, J. Yang, and T. Cui, "Study of pore pressure change during mining and its application on water inrush prevention: a numerical simulation case in Zhaogezhuang coalmine, China," Environmental Earth Sciences, vol. 71, no. 5, pp. 2115-2132, 2014.

[27] Z. Q. Chen, X. X. Miao, and W. Q. Liu, “Analysis on stability of parametric system of seepage flow in wall rock affected by mining," Journal of Central South University of Technology, vol. 35, no. 1, pp. 129-132, 2004.

[28] Y. K. Cheng, Z. Q. Chen, X. X. Miao et al., "Testing study on permeability of non-Darcy flow in post-peak sandstone," Chinese Journal of Rock Mechanics and Engineering, vol. 23, no. 12, pp. 2005-2009, 2004.

[29] Q.-L. Ding, F. Ju, S.-B. Song, B.-Y. Yu, and D. Ma, “An experimental study of fractured sandstone permeability after high-temperature treatment under different confining pressures," Journal of Natural Gas Science and Engineering, vol. 34, pp. 55-63, 2016. 


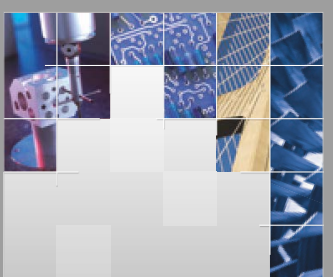

\section{Enfincering}
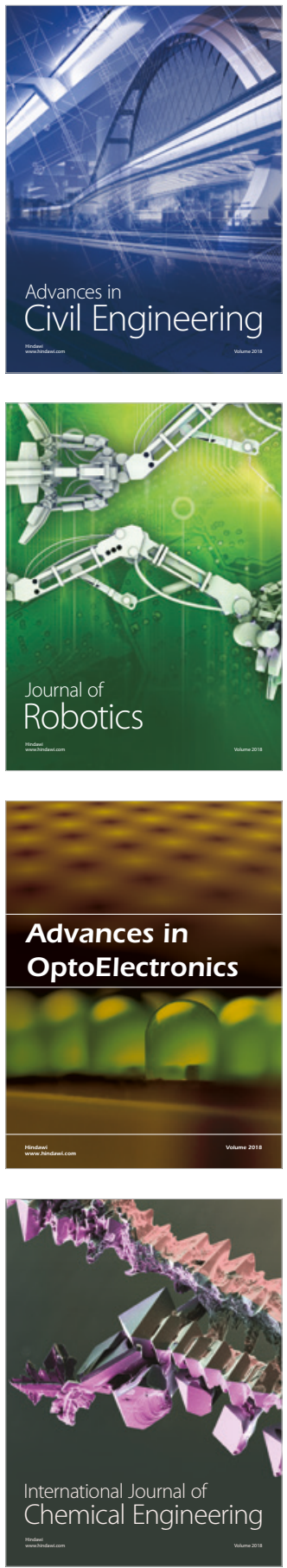

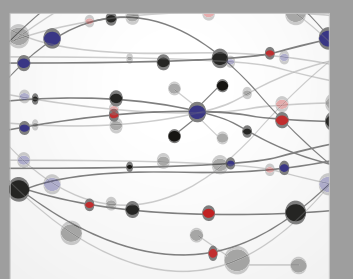

\section{Rotating \\ Machinery}

The Scientific World Journal

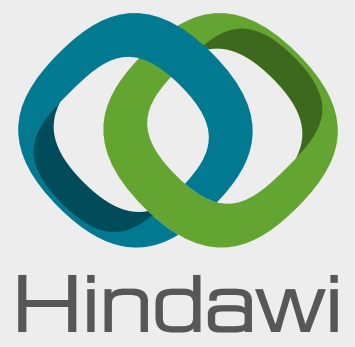

Submit your manuscripts at

www.hindawi.com
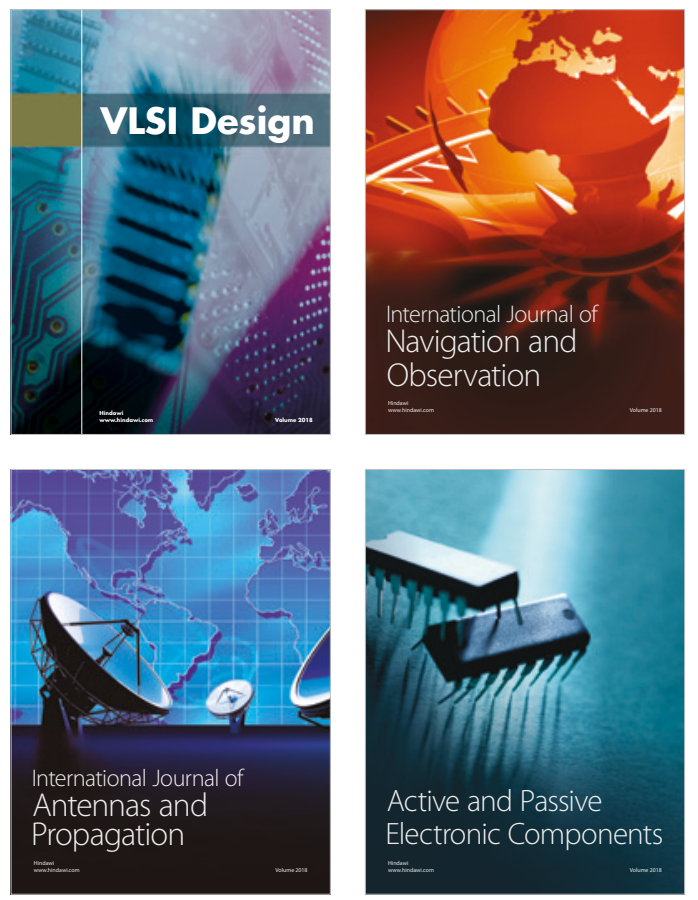
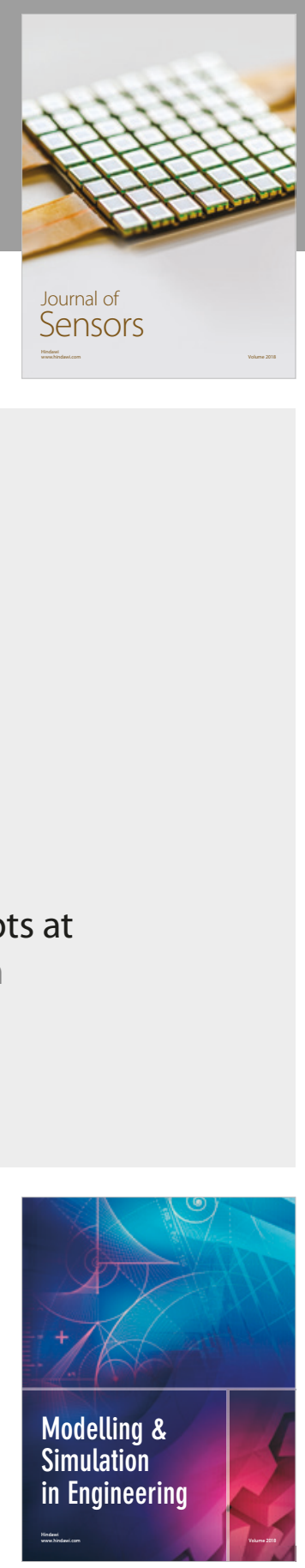

\section{Advances \\ Multimedia}
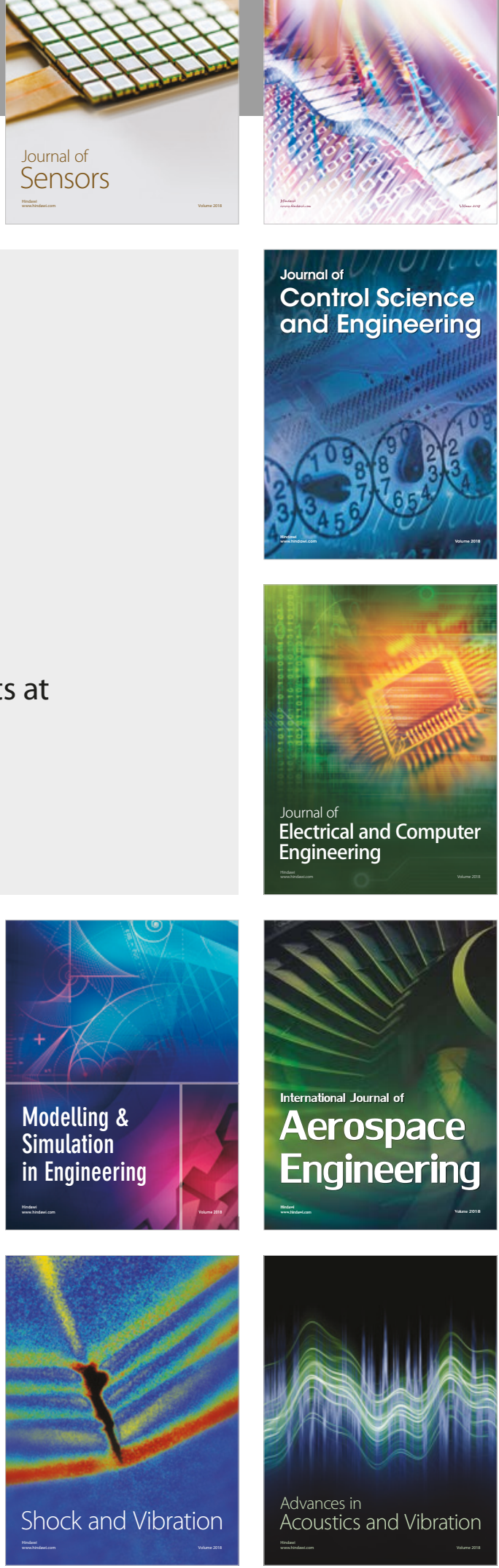